\section{Canada tries to limit nanotech brain drain}

C anada has traditionally lost some of its best and brightest minds to the United States, mainly because it cannot compete with the resources of an economy ten times the size of its own. And nanotechnology has been no exception.

Martin Moskovits recently moved from the chair of the University of Toronto's chemistry department to become dean in mathematics, life and physical sciences at the University of California at Santa Barbara. "In nanotechnology in Canada, we're slow off the mark," he says. "We haven't quite analysed appropriately what's made hot technological economies like the United States and Europe great."

More funding for basic research, with less constraints on practical outcomes, has stoked the field in the United States. And Moskovits hopes that Canada will adopt such an approach to staunch the flow of researchers south.

Scientists at Canada's National Research Council (NRC) are working to do just that. They are pushing the government to create a nanotechnology institute, and are hoping that the recent federal research funding largesse might allow them to succeed. The Liberal government increased funds for research and innovation in its February budget by Can $\$ 4.1$ billion (US $\$ 2.6$ billion). And in its election campaign material, it has promised to "at least double" those expenditures (see Nature404, 8; 2000).

Robert Wolkow, leader of the NRC's Scanning Tunneling Microscopy Group, says a large part of Canada's talent in the nanoworld is at the NRC, but these researchers will not benefit from the recent funding bonanza because the increases are directed at strengthening universities. "It's tragic," Wolkow says. "It's already leading to the departure of some really hot people."

With the support of others, Wolkow is

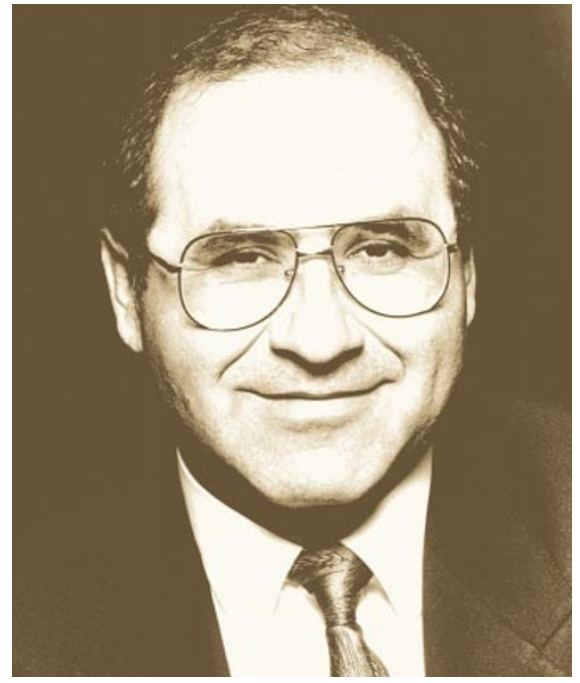

Despite working abroad, Martin Moskovits hopes that Canada can make its mark in nanotech.

"pushing for a radically different kind of NRC institute, where globally competitive salaries would be raised by some imaginative means and the very best [scientists attracted], not just from Canada but from everywhere."

Wolkow, a Canadian who, after graduating from the University of Toronto joined IBM in New York for a postdoc, had the good fortune to work with one of the first scanning tunnelling microscopes. He did the first study that showed a chemical reaction on an atomby-atom scale, which got him a job at Lucent Technologies' Bell Labs in New Jersey. There he built the first tuneable-temperature cryogenic scanning tunnelling microscope, which uses surface temperature to freeze reactions or allow them to continue at a controlled rate.

Despite the lack of a strong infrastructure, Canadian scientists have continued to advance nanotechnology. Wolkow and colleagues recently created one-dimensional organic structures on a silicon surface by

\title{
Nanotech undergrad course available
}

The University of Toronto will next year offer a nanoengineering undergraduate programme that combines chemistry, physics and materials science engineering.

Douglas Perovic, professor of applied science and engineering, says that the programme has already sparked a huge response. Students will be recruited from the university's engineering science course, but others can apply. The curriculum will open up four new professorships, as well as new positions in electrical computer engineering, physics and chemistry.

The new course involves seven university units: the materials science, physics, chemistry, chemical engineering, applied chemistry, mechanical and industrial engineering departments, and the institute for biomaterials and biomedical engineering. During the first two years, students will concentrate heavily on maths and physics, but in the final two years they will specialize in nanoengineering-type subjects. In the fourth year they will prepare a research thesis, as is done in masters programmes. In addition, they will be able to select groups of courses in their individual fields of interest.

combining scanning tunnelling microscopy and self-directed growth techniques. They hope that this technique could pave the way for assembling molecular wires on the nanotech equivalent of microchips.

There are other bright spots on the Canadian horizon. Nobel laureate John Polanyi and postdoctoral associates Ping-He Lu and Duncan Rogers at the University of Toronto have developed a technique for imprinting the structures of molecules on underlying substrates such as silicon. Work which could lead to methods for making microscopic structures for molecular electronics.

In eastern Canada, Bruce Balcom at the University of New Brunswick has adapted magnetic resonance imaging (MRI) to observe and quantify changes taking place in materials in space and over time. He says the university's MRI Research Centre is the only one in Canada and the only university-based laboratory of its kind in North America. Its techniques can be used with biological structures in vivo and with a large range of materials such as concrete, polymers, composites and microporous solids.

Harry Ruda, who directs the Energenius Centre for Advanced Nanotechnology (ECAN) at the University of Toronto, is a leader in so-called collective effects leading to quantum computing systems. ECAN was founded in 1997 with matching Can $\$ 45$ million awards from private sources, the Ontario government and the university. The centre carries out research and training in semiconductor nanotechnology, and has joint projects with the NRC, Cornell University and the University of North Carolina at Chapel Hill.

Ruda says that the centre is different because of its interdisciplinary focus on fabrication methods for nanostructures, and in exploring and exploiting collective effects to make novel electronic and photonic devices. ECAN seeks applications from graduate students and post-doctoral researchers, and encourages its members to participate in international exchange programmes.

Although Moskovits is now in the United States, he maintains a Canadian connection. He leads a programme in molecular electronics for the Canadian Institute for Advanced Research, involving self-assembly and synthesis of nanoelectronic materials. The institute is a 'university without walls', and serves to reduce the brain drain by enlisting the talents of researchers worldwide - including Canadians who have left Canada.

David Spurgeon is Nature's Canada correspondent.

MRI Research Centre

www.unb.ca/physics/mri/index.html

Energenius Centre for Advanced Nanotechnology

www.utoronto.ca/ ecan

NRC Steacie Institute for Molecular Sciences

www.nrc.ca/sims

NRC Institute for Molecular Sciences

www.nrc.ca/ims 